\title{
Artificial selection for odor-guided behavior in Drosophila reveals changes in food consumption
}

\author{
Elizabeth B. Brown ${ }^{1}$, Cody Patterson ${ }^{1}$, Rayanne Pancoast ${ }^{1,2}$ and Stephanie M. Rollmann ${ }^{1 *}$ (D)
}

\begin{abstract}
Background: The olfactory system enables organisms to detect chemical cues in the environment and can signal the availability of food or the presence of a predator. Appropriate behavioral responses to these chemical cues are therefore important for organismal survival and can influence traits such as organismal life span and food consumption. However, understanding the genetic mechanisms underlying odor-guided behavior, correlated responses in other traits, and how these constrain or promote their evolution, remain an important challenge. Here, we performed artificial selection for attractive and aversive behavioral responses to four chemical compounds, two aromatics (4-ethylguaiacol and 4-methylphenol) and two esters (methyl hexanoate and ethyl acetate), for thirty generations.

Results: Artificial selection for odor-guided behavior revealed symmetrical responses to selection for each of the four chemical compounds. We then investigated whether selection for odor-guided behavior resulted in correlated responses in life history traits and/or food consumption. We found changes in food consumption upon selection for behavioral responses to aromatics. In many cases, lines selected for increased attraction to aromatics showed an increase in food consumption. We then performed RNA sequencing of lines selected for responses to 4ethylguaiacol to identify candidate genes associated with odor-guided behavior and its impact on food consumption. We identified 91 genes that were differentially expressed among lines, many of which were associated with metabolic processes. RNAi-mediated knockdown of select candidate genes further supports their role in odor-guided behavior and/or food consumption.
\end{abstract}

Conclusions: This study identifies novel genes underlying variation in odor-guided behavior and further elucidates the genetic mechanisms underlying the interrelationship between olfaction and feeding.

Keywords: Drosophila, Olfaction, Feeding, RNA sequencing, RNA interference

\section{Background}

Sensory systems enable organisms to interact with the environment. Whether avoiding a predator, seeking a mate, or searching for food, these behaviors are mediated through the sensory detection and subsequent processing of environmental cues. In the case of olfaction, aversive and attractive olfactory cues are used, for instance, by organisms to locate and evaluate food resources. Moreover, olfactory cues can also influence other traits, such as organismal life span and starvation

\footnotetext{
* Correspondence: stephanie.rollmann@uc.edu

'Department of Biological Sciences, University of Cincinnati, Cincinnati, $\mathrm{OH}$ 45221-0006, USA

Full list of author information is available at the end of the article
}

resistance [1-5]. Given their importance to survival and reproduction, behavioral geneticists have long sought to understand the proximate mechanisms underlying olfactory behavior, its interrelationship with other traits, and the mechanisms governing or constraining its phenotypic evolution. Thus, remarkable progress has been made in uncovering the neural circuitry underlying the detection of chemical cues [6-8]. However, understanding how sensory input is processed to result in divergent behavioral responses (olfactory attraction or aversion) and the genetic mechanisms that underlie its association with traits such as feeding and life span remains an important challenge. 
Drosophila melanogaster has emerged as a model system for investigating the genetic factors underlying the detection and discrimination of olfactory cues $[6,8]$. Odorants are detected by odorant receptors expressed in olfactory sensory neurons (OSNs) located on either of two olfactory organs, the third segment of the antenna or the maxillary palp. Each OSN typically expresses a single odorant receptor (OR) type and projects its axons to a distinct glomerulus in the antennal lobe [9-13]. These odorant receptors comprise a family of sixty genes that together with the highly conserved coreceptor, Orco, are believed to form ligand-gated ion channels [10, 14-18]. First order OSNs form synaptic connections with second order projection neurons, which extend their axons to the mushroom body and lateral horn regions of the brain [19-22]. The resulting spatial and temporal representation of glomerular activity allows for the discrimination among the diverse odors present in the environment [10, 23, 24]. More recently, studies have also focused on the identification of genes associated with variation in olfactory behavior through the use of candidate gene association studies [25-29] as well as genome-wide association (GWA) mapping [30-32]. These analyses identified genes that form a pleiotropic network of interactions and are largely involved in nervous system development and function.

In addition, studies in Drosophila have focused on examining the interrelationship between olfaction, feeding, and life history traits, including longevity and starvation resistance $[3,4,33,34]$. Changes in sensory perception, for example, through silencing of the coreceptor Orco, resulted in extended longevity and increased resistance to starvation. Altered metabolism was also observed, with sex-specific changes in triglyceride levels [3]. Additionally, the olfactory system is also associated with mediating feeding [35-38]. A starvationdependent shift in OSN sensitivity via short neuropeptide F, a fly homolog of neuropeptide Y (NPY) [39], and insulin signaling regulates food search behavior [40]. Moreover, neurons expressing neuropeptide $\mathrm{F}$ ( $\mathrm{dNPF}$ ) respond to food odors, increasing in activity with increased food-odor attractiveness [41].

Here, we conduct artificial selection experiments to investigate the mechanisms underlying olfactory behavior and correlated responses with other traits. We independently selected for attractive and aversive behavioral responses to two aromatic compounds (4-ethylguaiacol and 4-methylphenol) and two esters (ethyl acetate and methyl hexanoate) for thirty generations. These odorants are a natural byproduct of yeast fermentation [42-45], a component of the feeding and breeding substrate of Drosophila. We then used these artificially selected lines to investigate potential relationships with other traits and found odor- and sex-specific differences in food consumption. We subsequently performed RNA sequencing (RNA-seq) experiments to identify changes in gene expression using lines selected for differences in behavioral responses to the odorant 4-ethylguaiacol and examined the role of a subset of these candidate genes in mediating odor-guided behavior and food consumption.

\section{Results}

\section{Selection for odor-guided behavior}

To understand the genetic mechanisms underlying shifts in odor-guided behavior, we performed artificial selection experiments using the Flyland population, an outbred population derived from the Drosophila Genetic Reference Panel [46]. We measured its behavioral responses to four odorants, 4-ethylguaiacol (4EG), 4methylphenol (4MP), methyl hexanoate $(\mathrm{MH})$, and ethyl acetate (EA), at several different concentrations. We observed concentration-specific differences in behavioral responses to each odorant tested (Fig. 1a-d). Based on these results, we independently generated three replicate high and low lines selected for attractive or aversive behavioral responses to each odorant, as well as three replicate unselected (control) lines. After seven generations, mean high and low behavioral responses to all odorants significantly diverged relative to the controls, and plateaued at approximately generation ten (Fig. 1e-h, Additional file 1: Table S1). The response to selection was symmetrical, with responses of the controls intermediate between the high and low lines (Fig. 1i-l). No significant changes in locomotion were observed among the selection regimes (Additional file 2: Figure S1).

\section{Correlated responses to selection for odor-guided behavior}

Changes in olfactory perception have been shown to affect life history traits, such as longevity and starvation resistance [3-5]. To test whether artificial selection for odor-guided behavior resulted in correlated responses in these traits, we measured longevity and starvation resistance across all four selection regimes. Overall no significant differences in life span were observed (Additional file 3: Figure S2; Additional file 1: Table S3). Measurements of starvation resistance, a trait often positively correlated with life span [47], also revealed no differences among lines in all four selection regimes (Additional file 4: Figure S3; Additional file 1: Table S3). One exception to these results was found for measurements of life span among the MH selected lines. Females selected for increased attraction to $\mathrm{MH}$ had a significant increase in life span relative to the control and low lines (Additional file 3: Figure S2).

Alterations in chemosensory perception can also influence feeding behavior [35-38]. We therefore investigated 

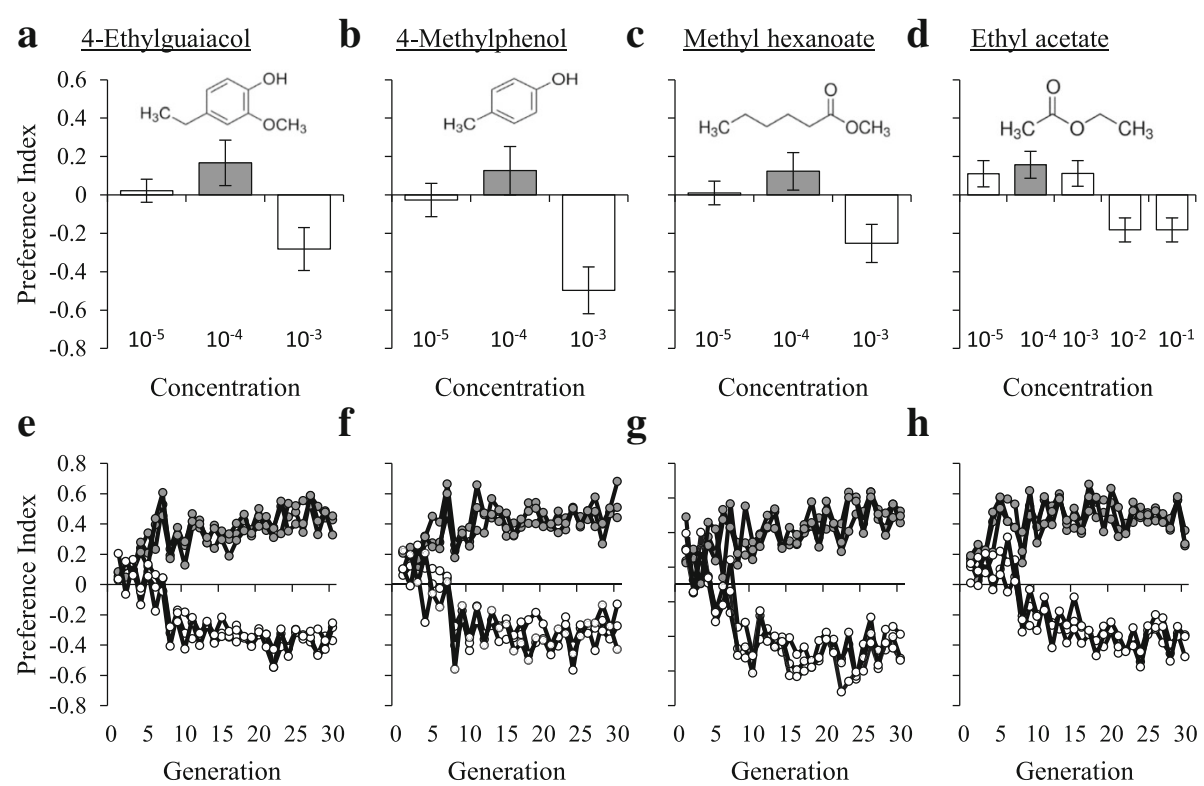

Concentration

g
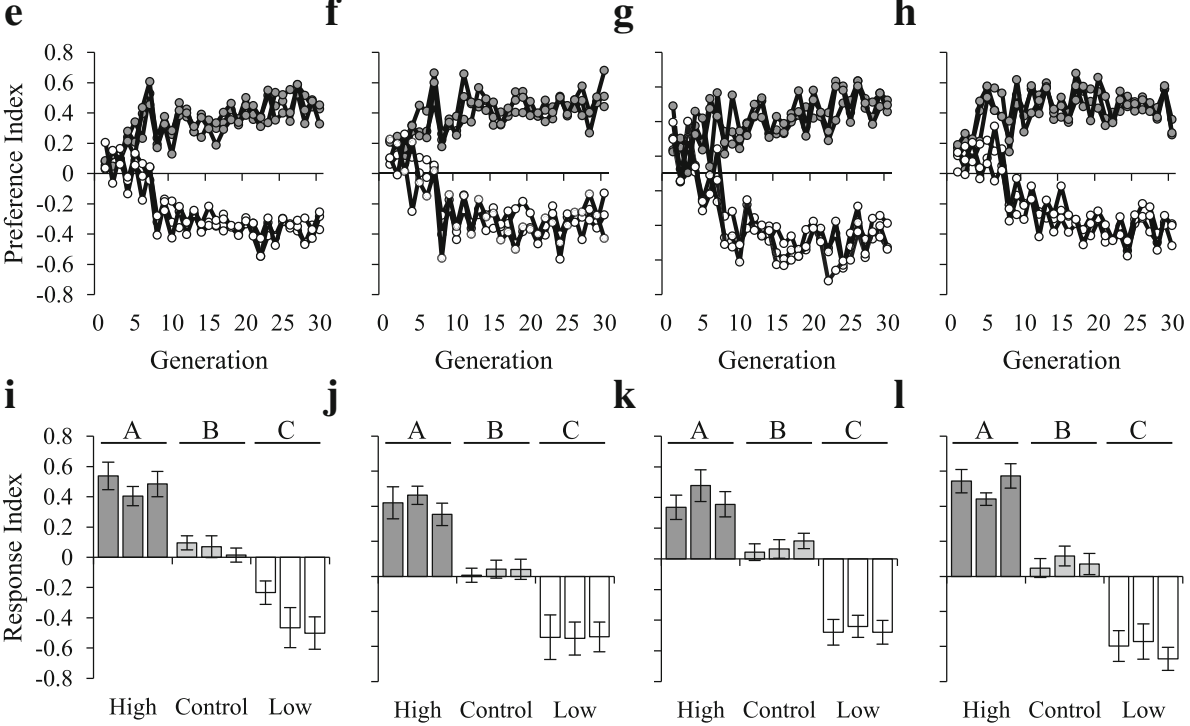

$\mathbf{k}$
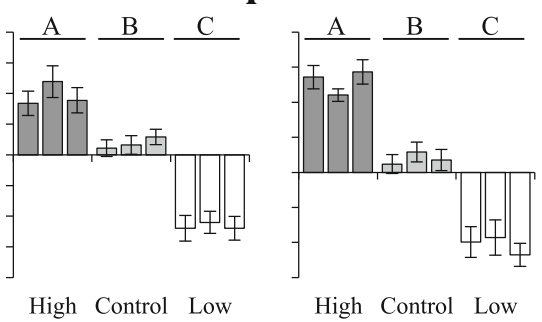

Fig. 1 Odor-guided behavioral responses to four odorants. Row 1: Dose response curves of the base population to four odorants. Preference indexes for (a) 4-ethylguaiacol, (b) 4-methylphenol, (c) methyl hexanoate, and (d) ethyl acetate are shown. Gray bars indicate the concentration used in the artificial selection experiments. Data shown are means \pm SE. $N=20$. Row 2: Phenotypic response to artificial selection for odor-guided behavioral responses to (e) 4-ethylguaiacol, (f) 4-methylphenol, (g) methyl hexanoate, and (h) ethyl acetate. Mean preference index at each generation for the three replicate high selected lines (gray filled dots) and three low selected lines (white filled dots) are shown. $N=6$. Row 3: Symmetrical response to selection for (i) 4-ethylguaiacol, (j) 4-methylphenol, (k) methyl hexanoate, and (I) ethyl acetate. Data shown are means \pm SE. Letters indicate $P<0.05$ using Tukey's post hoc test. $N=20$

whether changes in odor-guided behavior were associated with changes in food consumption using the CAFE assay [48]. When fed a standard liquid diet of sucrose and yeast extract, we observed significant sex-specific differences in food consumption among the $4 \mathrm{EG}$ and 4MP selected regimes in which high lines generally consumed significantly more than low and control lines (Fig. 2). In the case of lines selected for responses to 4EG, food consumption was significantly increased in males in the high selected lines, with the same trend apparent in females. For lines selected for responses to $4 \mathrm{MP}$, food consumption was significantly increased in females in the high selected lines, with again a similar trend observed in males. This pattern of food consumption was not observed for lines selected for responses to the esters, $\mathrm{MH}$ and EA. In general, no significant changes in food consumption were observed among these lines, with the exception of males selected for responses to EA, in which both high and low lines showed increased consumption relative to the control.

Food consumption of the 4EG and 4MP selected lines were again tested, and differences in consumption observed using two additional diets. First, we replaced yeast extract with live Brettanomyces yeast. Regardless of sex, all 4EG and 4MP selected lines increased consumption overall. Moreover, consistent with previous results, we generally observed increased food consumption in high lines relative to low and control lines (Additional file 5: Figure S4a, b). Next, we fed flies a diet of sucrose only. We again observed significant differences in food consumption for both sexes, with high lines consuming more food than the low and control lines (Additional file 5: Figure S4c, d). Also, food consumption in the control lines remained below that of the low lines. Finally, we used a binary-choice assay to investigate whether sucrose supplemented with either 4EG or 4MP conferred differences in food preference [45]. Flies were 


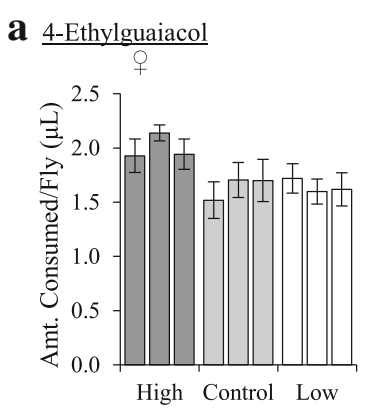

c Methyl hexanoate

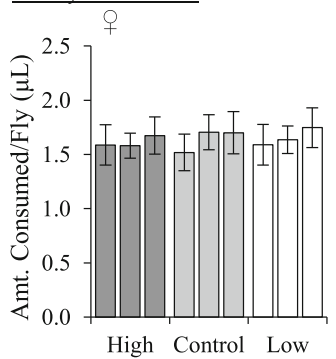

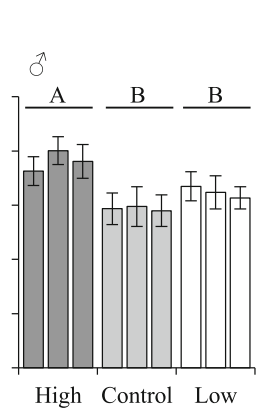

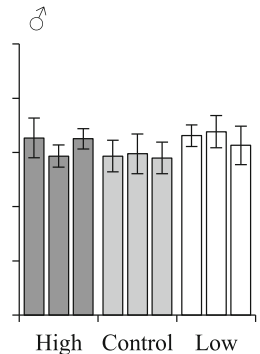

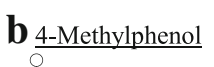

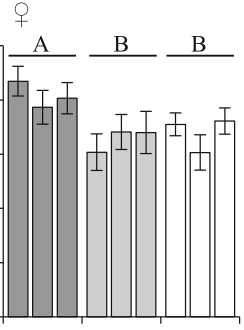

High Control Low

d Ethyl acetate

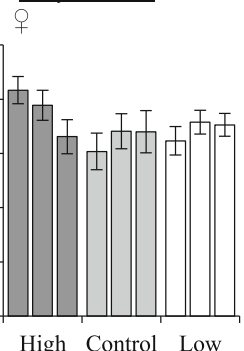

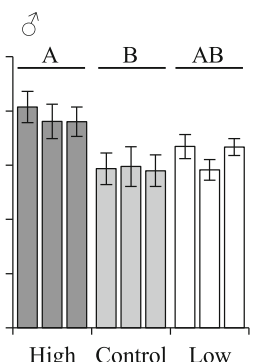

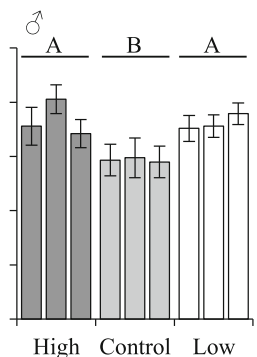

Fig. 2 Food consumption measurements of lines selected for increased and decreased behavioral responses to (a) 4-ethylguaiacol, (b) 4-methylphenol, (c) methyl hexanoate, and (d) ethyl acetate using the CAFE assay. The total amount of yeast extract consumed was measured. Data shown are means \pm SE for females (left) and males (right). Letters indicate $P<0.05$ using Tukey's post hoc test. $N=12$

given a choice between food with or without supplementation of odorant. We hypothesized we would observe an increase in preference for food supplemented with odorant in the high lines and reduced consumption in the low lines, given their attraction/aversion to each odorant, respectively. Interestingly, we found no significant differences in food preference, such that all selected lines equally, albeit mildly, preferred food supplemented with either 4EG or 4MP (Additional file 5: Figure S4e, f). Together, these results suggest that selection for behavioral responses to these aromatics results in correlated responses in feeding behavior with the high lines typically consuming more, irrespective of diet, but importantly that selection for increased attraction and aversion does not directly translate into corresponding changes in food consumption.

The changes in food consumption may result from changes in metabolic processes or from general differences in body mass [49]. To investigate whether selection for odor-guided behavior was also associated with changes in these traits, we measured dry mass in the 4EG and 4MP selected lines. For 4EG selected lines, no significant differences in body mass were observed (Additional file 6: Figure S5a). However, for the 4MP selected lines, the high selected lines weighed significantly more than the other lines (Additional file 6: Figure S5b). Measurements of metabolic processes (triglycerides, glucose, and glycogen) revealed no significant differences after adjustment for dry mass (Additional file 6: Figure S5c-h). One exception being males selected for behavioral responses to 4MP, in which the low lines had significantly lower glucose levels than the control lines, but neither of which were significantly different from the high lines. In short, for the 4EG and 4MP selection regimes, high lines consistently consumed more than low lines, however, these differences in food consumption cannot be clearly attributed to changes in the metabolic traits measured here.

\section{Transcriptional response to selection for odor-guided behavior}

To examine the genetic mechanisms underlying differences in odor-guided behavior and the correlated responses on feeding, we conducted RNA-seq analyses on lines selected for divergent responses to 4EG. This selection regime was chosen for further analysis because differences were observed between the high and low selected lines for both odor-guided behavior and food consumption, independent of mass. Differential gene expression was examined in whole heads to include in the analysis genes associated with the peripheral olfactory organs, the brain, as well as feeding organs. In total, we obtained 780,640,808 100 bp reads from 18 cDNA libraries. Of 753,144,236 reads that passed quality filtering, 95.32\% could be aligned to the Drosophila genome, and 98.64\% of the aligned reads mapped to uniquely (Additional file 1: Table S4, Additional file 1: Table S5). Of the 17,471 annotated genes [50], 9238 had at least one read per million in at least half the samples. This set of genes was used for subsequent statistical analyses. 
Differential gene expression was evaluated between the different combinations of selection regimes, i.e., high vs. control, low vs. control, and high vs. low. A total of 43,32 , and 45 genes were significantly differentially expressed in the high vs. control, low vs. control, and high vs. low comparisons, respectively (Additional file 4: Fig. 3a; Additional file 1: Table S68). Eleven genes were shared between high vs. low and low vs. control comparisons, thereby highlighting genes that may contribute to aversive behavioral responses to 4EG. Nine genes were shared between high vs. control and low vs. control comparisons which may consist of genes that are responsible for generalized changes in behavior, regardless of hedonic value, as these genes were differentially expressed regardless of selection for high or low behavioral responses. Nine genes were also shared between the high vs. control and high vs. low comparisons and could give insights into the genes responsible for attraction to 4EG and its link with food consumption (Fig. 3b). Finally, we chose to focus on the high vs. low differentially expressed genes for subsequent analyses. We assessed whether there was overrepresentation of Gene Ontology (GO) terms. No significant overrepresentation for any GO terms were found (Additional file 7: Figure S6). However, of the 45 significantly differentially expressed genes, 13 were annotated for the GO term metabolic process and four for response to stimulus.

\section{Functional tests of candidate genes}

To further assess the candidate genes significantly differentially expressed between high and low selected lines for their contribution to changes in odor-guided behavior and/or food consumption, we used RNA interference $[51,52]$ and the GAL4/UAS system [53] to knockdown gene expression. We selected a subset of 16 genes based on their statistical level of significance, their identification across treatments, and their GO classification. Since OSNs and projection neurons are two primary relay stations at which olfactory information is processed, we knocked down gene expression in OSNs expressing Or71a, an odorant receptor shown to be tuned to 4EG using the Or71a-GAL4 driver line, and in projection neurons of the antennal lobe using the GH146-GAL4 driver line [54]. We observed significant differences in odor-guided behavior for seven of the genes tested (Fig. 4a.b; Additional file 1: Table S9; CG6044, Cyp6a2, Egfr, grp, GstD2, tej, VepD), and differences in food consumption for 10 genes (Fig. 4c, d; Additional file 1: Table S9; Cdc6, CG6044, Cyp6a2, Egfr, grp, SoYb, Spn42Dc, tej, Tret1-2, VepD). RNAi targeting of six of these genes
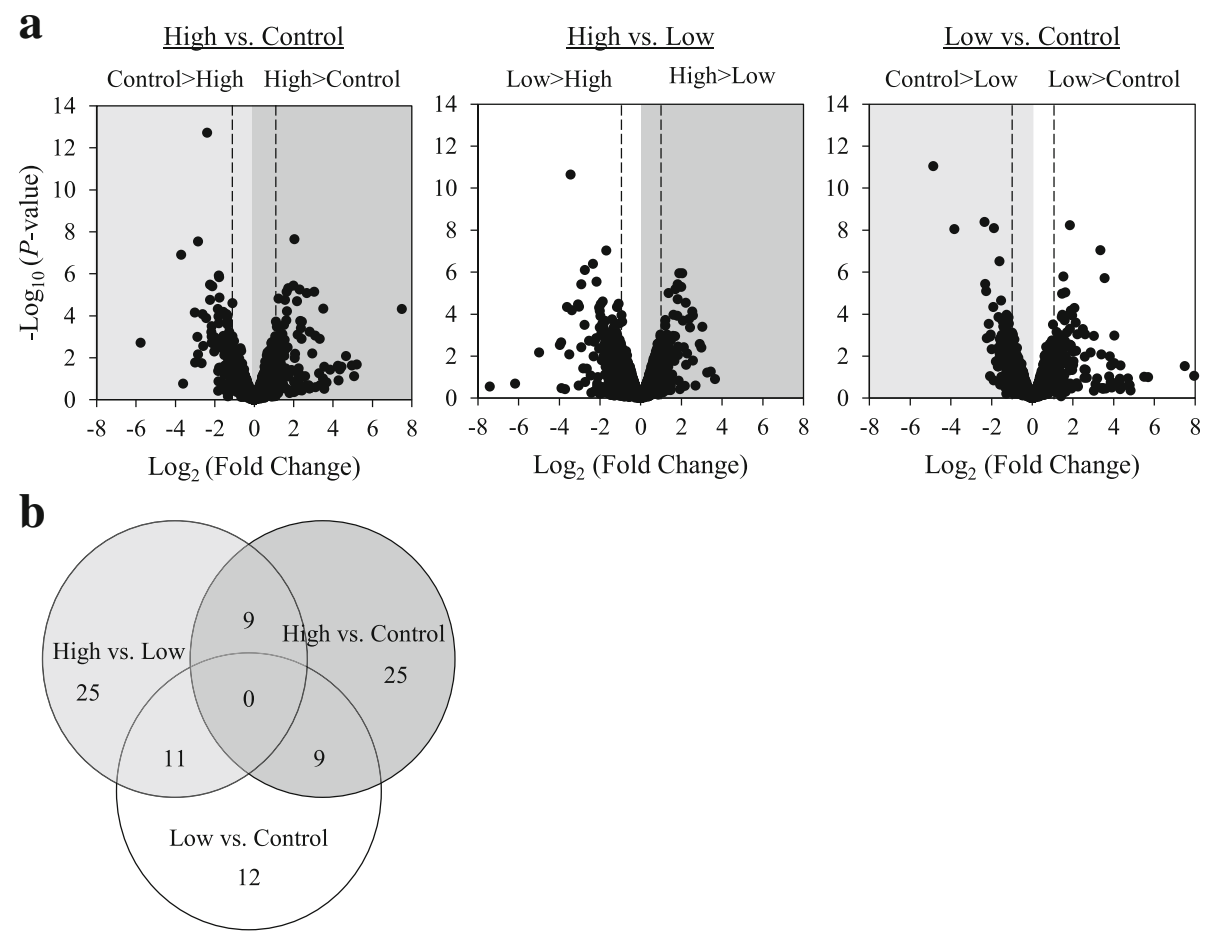

Fig. 3 RNA-seq analyses of genes differentially expressed among lines selected for 4-ethylguaiacol. (a) Volcano-plot of RNA-seq results for all pairwise comparisons. For each comparison, genes to the left of the > symbol are upregulated, while genes to the right are downregulated. Vertical dashed lines represent a two-fold cutoff. (b) Venn diagram illustrates the differentially expressed genes that overlap between each comparison 

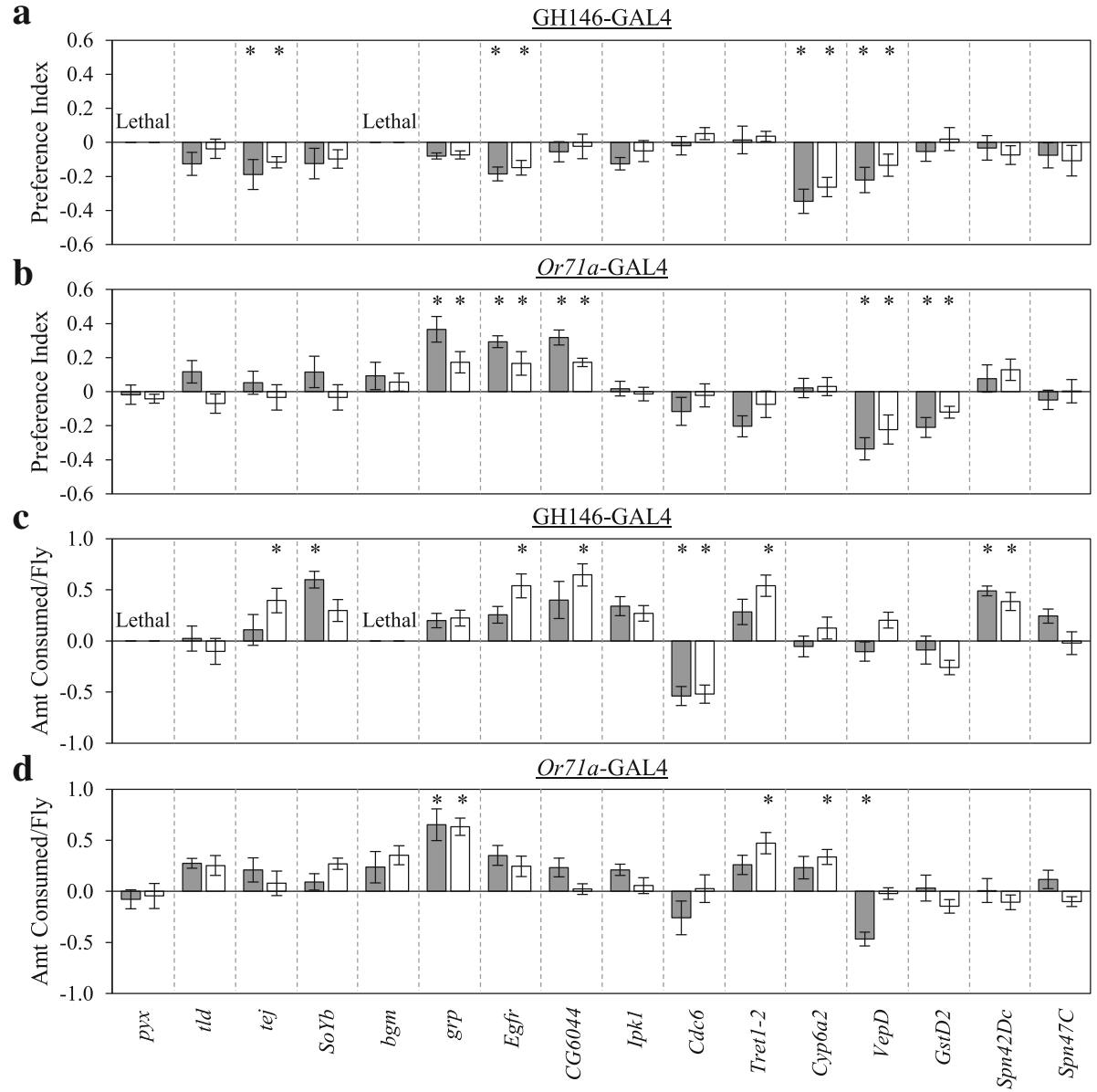

Fig. 4 Functional tests of candidate genes and their effects on (a), (b) odor-guided behavioral responses to 4-ethylguaiacol and (c), (d) food consumption. For each trait, the effects of RNAi-mediated knockdown of 16 candidate genes in either projection neurons of the antennal lobe (GH146-GAL4) or in Or71a-expressing neurons (Or71a-GAL4) were examined in both females (gray bars) and males (white bars). Values are deviations from the control. Error bars indicate SE. $*$ : $P<0.05 . N=10$

resulted in significant differences in both odor-guided behavior and food consumption (CG6044, Cyp6a2, Egfr, grp, tej, VepD). The effects on behavior depended on sex, and the gene and/or neuronal population targeted. For example, expression of grp-RNAi in Or71a-expressing OSNs resulted in increased behavioral responses to 4EG as well as an increase in food consumption. However, a similar positive response was not always observed, as was the case with RNAi-mediated knockdown of Egfr and $t e j$ in projection neurons.

\section{Discussion}

\section{Selection for odor-guided behavior}

Artificial selection is a powerful method that allows us to examine divergence in odor-guided behavioral responses and how selection for attraction and aversion may result in correlated responses with other traits. Using this approach, selection lines were generated for odor-guided behavioral responses to four odorants, two aromatics and two esters. The response to selection was symmetric, such that both lines selected for attractive and aversive behavioral responses significantly differed relative to control. We then used these artificially selected lines to investigate correlated responses with odor-guided behavior and observed changes in food consumption associated with selection for behavioral responses to aromatics.

These aromatic compounds are detected by receptors expressed in olfactory sensory neurons of the maxillary palp. Detection of olfactory cues via the maxillary palp has been posited to mediate taste enhancement [55], with OSNs from the palp projecting to both the antennal lobe as well as the subesophageal ganglion, the primary taste center of the brain [56]. More specifically, these odorants (4EG and 4MP) bind to odorant receptor 71a (Or71a), which is expressed in palp OSNs $[45,57,58]$. Odor-evoked responses of Or71a-expressing neurons are of particular interest because previous studies suggest 
that detection of ethylphenols, including 4EG, by these neurons serves as a proxy for the detection of dietary antioxidants. Moreover, thermogenetic activation of these neurons via expression of dTRPA1 resulted in changes in feeding [45]. Thus, together with previous findings, our study sets the stage for future dissection of how changes in the maxillary palp may affect these behaviors.

In this study, the bidirectional response to selection for behavioral responses to aromatics resulted in an asymmetrical effect on food consumption. Significant increases in food consumption were typically observed in the high lines, relative to the low and control lines, irrespective of diet. Furthermore, we hypothesized that olfactory aversion would be associated with reduced food consumption, particularly when food was supplemented with the 'aversive' odorant. In point of fact, this was not the case. Previous studies have suggested that the context in which an odor is detected can be an important modulator of behavior [59]. For example, $\mathrm{CO}_{2}$, a chemical compound emitted from stressed flies, results in robust aversive behavioral responses [60]. However, when this odorant is paired with food odors, the aversive response is suppressed [61, 62]. Such context dependent behavior is modulated at multiple levels of the olfactory circuitry, from the periphery to the brain. This study suggests that the mechanisms underlying olfactory behavior and food consumption are partially independent and again suggests that the behaviors may be context dependent.

Finally, correlated changes in food consumption may result from changes in metabolism or body mass [49]. Yet, for both selection regimes we observed little to no concomitant shift in traits associated with metabolism. It is possible that correlated changes in food consumption are indeed associated with changes in the metabolic traits measured here, but not at levels sufficient for detection. Alternatively, potential differences in other metabolic traits not measured in this study, such as metabolic rate, could underlie the observed differences in food consumption [63]. In the case of dry mass, a difference among lines was only observed in the 4MP selection regime despite changes in both food consumption and odor-guided behavioral responses being observed in both 4EG and 4MP selection regimes. This suggests that the mechanisms underlying variation in responses to these odorants may at least partially differ.

\section{Transcriptional response to selection for odor-guided behavior}

To further understand the mechanisms underlying the divergence in odor-guided behavior and its association with food consumption, we conducted an RNA-seq experiment using lines selected for attractive and aversive behavioral responses to 4EG. We hypothesized that we would identify odorant receptor and odorant binding protein genes, as these have been previously associated with variation in odor-guided behavior [25, 26, 28, 29, 64], most notably Or71a, because 4EG is a ligand of this receptor [45]. Contrary to our expectations, however, we did not observe differences in expression of Or71a, nor in any other odorant receptor or odorant binding protein genes. Interestingly, however, we did identify genes (Cyp6a8, Cyp6a20, Cyp6a2, Cyp4d1, GstD2) belonging to the cytochrome P450 and glutathione Stransferase families, which have been implicated in odor signal termination [65]. The rapid degradation of odors, and subsequent termination of the odor signal, enables an organism to appropriately behaviorally respond to volatile changes in the environment. Therefore, changes in the expression of these genes may alter odor perception. Moreover, of the 91 differentially expressed genes identified in our study, 19 were also identified in genome-wide association analyses (GWA) on odor-guided behavior (ACXD, bgm, Cdc6, CG5773, CG8785, CG9616, CG10064, CG10205, CG12374, CG14608, CG31809, CG34273, CG43448, Cpr66D, Cyp6a8, Egfr, Hel89B, luna, pwn) [30-32]. These overlapping candidate genes were identified despite using different odorants with varying valence, thereby suggesting that they indeed may function in odor-guided behavior regardless of odor intensity or hedonic value. Finally, our analyses revealed novel genes not previously implicated in mediating odorguided behavior and afford new insights into the genetic mechanisms underlying these behavioral responses.

Given the observed differences in food consumption, we also hypothesized that we would identify genes involved in the insulin signaling and dNPF pathways, as both pathways are known to regulate multiple aspects of feeding behavior [66-69]. However, no differentially expressed genes were associated directly with these pathways. This can possibly be attributed to their high degree of conservation $[39,70]$, given that many of these genes are selectively constrained [71, 72]. However, our analyses did reveal differential expression of genes involved in metabolism (bgm, CG2469, CG10116, CG10962, CG33958, Cyp4d1, GstD2, HIP, Ipk1, phr, $S P 1029, t e j, t l d)$. Our analyses also revealed two genes identified in GWA analyses to be associated with variation in food consumption (CG43448, Egfr) [73], and three that overlap with the genomic response to selection for increased feeding (CG14696, Egfr, tld) [74]. The identification of these candidate genes in our study raises the possibility that they function at the interface between olfaction and feeding. 


\section{Functional assessment of candidate genes}

We functionally assessed the effects of 16 candidate genes in Or71a-expressing neurons and projection neurons of the olfactory system. RNAi mediated targeting of eleven candidate genes resulted in changes in olfactory and/or food consumption. The remaining five genes did not significantly influence behavior. We cannot exclude the possibility, however, that these genes influence these traits through other mechanisms not tested in this study. Of those that did influence behavior in our study, several genes were of note. RNAi-targeting of Epidermal growth factor receptor $(E g f r)$ resulted in a significant decrease in attraction when it was knocked down in projection neurons, but an opposite effect in Or71a-expressing neurons. This gene plays an extensive role in development, such as in cell fate specification [75-78]. Additionally, it has been implicated in GWA studies of Drosophila olfactory and feeding behaviors [32, 73] as well in mammalian obesity [79, 80]. Moreover, RNAi-mediated knockdown of Trehalose transporter 1-2 (Tret1-2) resulted in increased food consumption in males. A structurally similar gene, Tret1-1, regulates the release of trehalose, the primary sugar in insect hemolymph [81]. Although, Tret1-2 does not function in trehalose transport [81], our results suggest a role for Tret1-2 in mediating food consumption.

Finally, perhaps one of the most intriguing genes was grapes (grp). This gene had effects on both odor-guided behavior and food consumption. The directionality of grp expression is similar in both our RNA-seq analyses and RNAi experiments. High selected lines had significantly lower grp expression than low selected lines, and knockdown of grp expression in Or71a-expressing neurons recapitulated this pattern with a significant increase in attraction to 4EG and significantly higher amounts of food consumed relative to the control. This gene is expressed in the antenna [82], involved in sensory organ development [83], and has been previously identified in a GWA analysis on odor-guided behavior [32]. Moreover, grp belongs to the calcium/calmodulin-dependent protein kinase gene family [84-86]. Another member of this gene family, $\mathrm{Ca}^{2+} /$ calmodulin kinase II (CaMKII), is not differentially expressed in this study, but is well known for its role in olfaction. This gene regulates the termination of olfactory signaling by olfactory adenylyl cyclase [87] and has been implicated in olfactory memory formation [88]. Members of the calcium/calmodulin-dependent protein kinase family have also been implicated in the regulation of metabolism. In rats, administration of NPY to the hypothalamus, a region of the brain controlling appetite [89], increases CaMKII activity [90]. Two additional members of this family, CaMKI and CaMKIV, stimulate insulin biosynthesis in pancreatic $\beta$-cells in response to glucose stimulation
[91]. The involvement of this gene family in olfaction as well as the metabolic control of feeding sets the stage for future investigations into the molecular mechanisms by which grp affects olfactory perception and food consumption.

\section{Conclusions}

Artificial selection for attractive and aversive behavioral responses to four odorants revealed symmetrical responses to selection, such that the selection lines differed in their behavioral responses relative to the controls. Measurements of food consumption were associated with selection for behavioral responses to $4 \mathrm{EG}$ and 4MP. Differential expression analyses revealed genes involved in metabolism in lines selected for behavioral responses to 4EG. RNAi mediated knockdown of gene expression of several of these candidate genes revealed their role within specific neuronal populations of the olfactory system and sets the stage for future work on the functional mechanisms by which these genes affect both odor-guided behavior and food consumption. This work provides novel insights into the genetic architecture underlying olfactory behavior and its association with feeding behavior.

\section{Methods}

\section{Drosophila maintenance and husbandry}

Flies were reared on standard cornmeal/agar/molasses media at $25{ }^{\circ} \mathrm{C}$ under a $12 \mathrm{~h}$ light-dark cycle. Flyland was kindly provided by Dr. Trudy F. Mackay [46]. Transgenic RNAi lines obtained from the Drosophila Transgenic RNAi Project (Harvard Medical School) include: pyx (31297), tld (51507), tej (36879), SoYb (36881), bgm (55918), grp (36685), Egfr (36773), CG6044 (28610), Ipk1 (35250), Cdc6 (55734), as well as their coisogenic controls attP2 (36303) and attP40 (36304) [51, 52]. RNAi lines were also obtained from the Vienna Drosophila Resource Center [92]. These lines include: Tret1-2 (v40980), Cyp6a2 (v48849), VepD (v103259), GstD2 (v109123), Spn42Dc (v13263), Spn47C (v100328) as well as the control lines $w^{1118}$ (v60000) and $y, w[1118] ; P\left\{a t t P, y[+], w\left[3^{\prime}\right]\right.$ (v60100). Each RNAi line was crossed to the following drivers: GH146-GAL4 (gift from F. Hamada, University of Cincinnati) and Or71a-GAL4 (23122). Controls for genetic background were generated by crossing GAL4 driver lines to the appropriate host strain used to generate the RNAi line.

\section{T-maze assay}

Behavioral assays were conducted as previously described [93], with minor modification. Briefly, thirty flies were placed into the center of a T-maze apparatus and allowed to acclimate for one minute. Flies were then given a choice between the two arms of the maze, one 
arm containing the diluted odorant and the other containing the paraffin oil vehicle. Both arms had airflows of $500 \mathrm{~mL} / \mathrm{min}$. After one minute, the number of flies on each side were counted. The preference index (PI) was calculated using the formula: $\mathrm{PI}=(\mathrm{O}-\mathrm{N}) /(\mathrm{O}+\mathrm{N})$, where $\mathrm{O}$ is the total number of flies on the odor side, $\mathrm{N}$ is the total number of flies on the side not containing odor. A positive PI is indicative of attraction to the odor (with a maximal response of +1 ), whereas a negative PI indicates repulsion (with a maximal response of -1 ). All assays were conducted in the morning in the dark at $25{ }^{\circ} \mathrm{C}$ and $70 \%$ humidity. All flies were aged 3-7 days post-eclosion and were starved overnight on $1 \%$ agar (MoorAgar Inc.; Rocklin, CA). Each line and sex were tested separately and the arm from which odor was emitted was randomized each day of testing. RNA interference experiments were conducted using the same protocol as above.

\section{Artificial selection}

Artificial selection experiments were conducted for behavioral responses to four odorants: 4-ethylguaiacol (SigmaAldrich; St. Louis, MO), 4-methylphenol (Sigma-Aldrich), methyl hexanoate (Sigma-Aldrich), and ethyl acetate (Sigma-Aldrich), using Flyland as the base population [45]. All behavioral assays were performed at $0.01 \%$. To commence selection, we measured behavioral responses of virgin females and males to each odorant. Upon completion of each assay, flies were collected from the odorand non-odor sides of the T-maze. Flies collected from the odor side were used to establish the high lines, while files from the non-odor side were used to establish the low lines. Behavioral tests were performed until a minimum of 25 females and 25 males for each of three replicate high and low responding lines were obtained for each odorant. To establish the control lines, assays were conducted in which there was no odor present in the T-maze. Flies were then collected from one side of the T-maze, selected at random. This selection regime was repeated each generation for 30 generations. Symmetrical responses to selection were assessed at generation 18 .

\section{Locomotion}

Locomotor reactivity was measured as described previously [94]. Briefly, single flies were placed into vials containing standard food media and acclimated overnight. Locomotion was quantified by recording the amount of time a single fly was active over a $45 \mathrm{~s}$ time period immediately following a mechanical disturbance. For each line and sex, 10 replicate measurements were taken at generation 18 .

\section{Correlated responses to selection}

Food consumption was measured using the CAFE assay $[48,95]$. Briefly, each chamber contained a calibrated glass micropipette (VWR, Radnor, PA) filled with $5 \mu$ of liquid medium that was inserted through a foam plug and held in place with a pipette tip. At the bottom of each chamber, $1 \%$ agar was used as a water source. Flies were habituated to the chambers for $24 \mathrm{~h}$ with ad libitum food prior to testing. Food consumption was measured for $24 \mathrm{~h}$. For feeding preference experiments, feeding preference was calculated using the formula: $(\mathrm{O}$ $-\mathrm{C}) /(\mathrm{O}+\mathrm{C})$, where $\mathrm{O}$ is the amount of food consumed with supplementation of odorant and $\mathrm{C}$ is the amount of food consumed without odorant [45]. Identical chambers without flies were maintained to assess evaporation and the total amount consumed was adjusted accordingly. Flies tested were 2-4 days posteclosion. Unless otherwise specified, the liquid food was 5\% sucrose (Sigma-Aldrich), 5\% yeast extract (Fisher Scientific, Hampton, NH) or live Brettanomyces yeast (William's Brewing, San Leandro, CA), and 0.001\% FD\&C blue dye (Spectra Colors Corp., Kearny, NJ). For each line and sex, 12 replicates housing five flies each were tested.

For dry mass, longevity, and starvation resistance measurements, flies were reared as larvae at constant density of 50 larvae per vial. To measure dry mass, flies were separated by sex and placed on fresh media for $24 \mathrm{~h}$ after which they were dried for $24 \mathrm{~h}$ at $70{ }^{\circ} \mathrm{C}$. For each line and sex, 10 replicate measurements were taken. Longevity was measured as previously described [96]. Briefly, 10 flies were placed into a vial and then scored every $24 \mathrm{~h}$. Flies were transferred to fresh media every 2-3 days, during which dead flies were removed. For each line and sex, eight replicate vials were measured. For starvation resistance, flies were starved on $1 \%$ agar and survival measured every $8 \mathrm{~h}$ until death. For each line and sex, eight replicate vials of 10 flies each were measured. All experiments were performed on mated flies. Longevity and starvation resistance were measured at generation 18 and dry mass at 26.

Triglyceride (TAG), glucose, and glycogen levels were calculated as previously described [97]. For each line and sex, three replicate measurements consisting of five adult flies were taken at generation 28. Each sample was homogenized in $100 \mu \mathrm{l} \mathrm{PBS}$, heat treated at $70^{\circ} \mathrm{C}$ for $10 \mathrm{~min}$, then flash frozen. Samples were subsequently thawed and assayed for glucose, glycogen and TAG content. Glucose and glycogen were quantified using the Glucose assay kit (Sigma-Aldrich). Glucose was measured directly from the homogenate, whereas glycogen was first digested to glucose during a 60 min incubation at $37{ }^{\circ} \mathrm{C}$ with $15 \mu \mathrm{l}$ amyloglucosidase solution at $1.5 \mathrm{U}$ $\mathrm{ml}^{-1}$ (Sigma-Aldrich), from which the previous glucose measurements were then subtracted. TAG levels were quantified by measuring glycerol content before and after digestion with Triglyceride Reagent (Sigma-Aldrich). TAG 
content was determined as the difference in glycerol content between the TAG-digested and TAG-undigested measurements.

\section{Statistical analysis}

A Shapiro-Wilk test was performed for each experiment to assess normality prior to subsequent statistical analysis (data not shown). For measurements of olfactory behavior, food consumption, and nutrient stores, we performed a nested mixed model analysis of variance (ANOVA) that accounted for the number of replicate lines within each selection regime (high, low and control): $\mathrm{Y}=\mu+$ Selection + Line (Selection) + Sex + Selection $x$ Sex + Line (Selection) $\mathrm{x}$ Sex $+\varepsilon$. Where Selection is the fixed effect of selection treatment (high, control, or low behavioral responses), Line is the random effect of replicate within each selection regime, Sex is the fixed effect of sex, and $\varepsilon$ indicates error. If no significant difference between sexes was observed, the data were pooled. Post-hoc analyses were conducted using Tukey's HSD test. For starvation resistance and longevity measurements, log-rank tests were performed for survivorship analyses. For RNAi experiments, significant differences between the knockdown and its corresponding isogenic control were assessed using Dunnett's tests for each sex. All data was analyzed using JMP 12.0 software (SAS Institute Inc., Cary, NC).

\section{RNA isolation and sequencing}

Whole heads from 100 female adult flies aged 3-7 days post-eclosion were hand dissected in the morning. Two independent biological replicates were collected for each of the three high, low, and control lines. Total RNA was isolated using an RNeasy Mini Kit (Qiagen, Valencia, CA, 74,104). Total RNA was provided to the Weill Cornell Medical College Genomics Resources Core Facility for subsequent RNA sequencing using standard protocols, during which cDNA libraries were generated from each sample, and then sequenced using Illumina HiSeq4000 to generate 100 bp reads.

\section{RNA-seq processing and analysis}

Adapters were removed from raw sequence reads using the program Trim Galore! (http://www.bioinformatics. babraham.ac.uk/projects/trim_galore), modifying the default parameters to allow a maximum error rate of zero. From there, the Cutadapt program was used to trim low quality sequences with Phred scores below 20 as well as remove reads shorter than $30 \mathrm{bp}$ from the analysis [98]. The remaining RNA-seq reads were then aligned to the Drosophila melanogaster reference genome (version 6.10) [50] using STAR [99]. Differential expression between selection regimes was assessed using the Bioconductor EdgeR package [100]. Raw read counts were filtered to keep only genes that contain at least one read per million in at least half the samples. The data were then normalized for library size using the calcNormFactors function. To identify the differentially expressed genes between high, low, and control selected lines, three comparisons were performed: (a) high vs low, (b) high vs control, (c) low vs control. For each comparison, the three replicate lines composing each high, low, and control treatments were pooled. To account for multiple testing, we applied a FDR of 0.10. The program Panther was used to assess whether there was overrepresentation of Gene Ontology (GO) terms [101, 102].

\section{Additional files}

Additional file 1: Table S1. Analyses of variance on odor-guided behavioral responses to artificial selection for each odorant at a given generation. Table S2. Analyses of variance on each trait measured. Traits include locomotor reactivity, longevity, starvation resistance, measurements of food consumption, dry mass, triglyceride levels, glucose, and glycogen. Table S3. Log-rank tests on longevity and starvation resistance

measurements. Table S4. Summary of RNA-Seq datasets for control and 4-ethylguaiacol selected lines. Total reads are the number of reads that have passed quality filtering for each sample. Aligned reads and percent aligned are the number and percent of total reads that could be aligned to the reference genome. Uniquely mapped and percentage mapped reads are the number and percentage of reads that mapped uniquely. Table S5. RNA-seq results for control and 4-ethylguaiacol selected lines. For each gene, its FlyBase ID and the total number of raw reads in each sample is provided. Table S6. Differentially expressed genes between control and high lines selected for behavioral responses to 4-ethylguaiacol. For each gene, the log2 fold change (FC) and the log2 counts per million (CPM) are listed. Also listed is the corresponding likelihood ratio (LR), its $P$-value $(P)$, and false discovery rate (FDR). Table S7. Differentially expressed genes between control and low lines selected for behavioral responses to 4-ethylguaiacol. For each gene, the log2 fold change (FC) and the log2 counts per million (CPM) are listed. Also listed is the corresponding likelihood ratio $(L R)$, its $P$-value $(P)$, and false discovery rate (FDR). Table $\mathbf{S 8 .}$ Differentially expressed genes between high and low lines selected for behavioral responses to 4-ethylguaiacol. For each gene, the log 2 fold change (FC) and the log2 counts per million (CPM) are listed. Also listed is the corresponding likelihood ratio $(\mathrm{LR})$, its $P$-value $(P)$, and false discovery rate (FDR). Table S9. Dunnett's test on odor-guided behavior and food consumption measurements for genes silenced in distinct neuronal subpopulations using RNA interference. For both odor-guided behavior and food consumption, the GAL4 driver lines tested, gene names, and $P$-value $(P)$ are listed. (XLSX $4068 \mathrm{~kb})$

Additional file 2: Figure S1. Locomotor reactivity of (a) 4-ethylguaiacol, (b) 4-methylphenol, (c) methyl hexanoate, and (d) ethyl acetate selected lines. Data shown are means \pm SE. $N=20$. (PDF $16 \mathrm{~kb}$ )

Additional file 3: Figure S2. Longevity of lines selected for $(\mathbf{a}, \mathbf{b}) 4$ ethylguaiacol, (c, d) 4-methylphenol, (e, f) methyl hexanoate, and ( $\mathbf{g}, \mathbf{h})$ ethyl acetate. For each line and sex, survivorship curves (panels 1 and 2) and median survivorship (panels 3 and 4) are shown. Data shown are median \pm SE for females and males (left and right columns, respectively). $N=70$. Letters indicate $P<0.05$ using Tukey's post hoc test. (PDF $126 \mathrm{~kb}$ )

Additional file 4: Figure $\mathbf{S 3}$. Starvation resistance of lines selected for (a, b) 4-ethylguaiacol, (c, d) 4-methylphenol, (e, f) methyl hexanoate, and $(\mathbf{g}, \mathbf{h})$ ethyl acetate. For each line and sex, survivorship curves (panels 1 and 2) and median survivorship (panels 3 and 4) are shown. Data shown are median $\pm \mathrm{SE}$ for females and males (left and right columns, respectively). $\mathrm{N}=70$. (PDF $111 \mathrm{~kb}$ )

Additional file 5: Figure S4. Feeding measurements of lines selected for increased and decreased behavioral responses to 4-ethylguaiacol and 4-methylphenol using the CAFE assay. Row 1: Food consumption measurements of live Brettanomyces yeast for lines selected for (a) 
4-ethylquaiacol and (b) 4-methylphenol. $N=12$. Row 2: Food consumption measurements of sucrose for lines selected for (c) 4-ethylguaiacol and (d) 4-methylphenol. $\mathrm{N}=12$. Row 3: Binary preference assay for food with or without supplementation of either (e) 4-ethylguaiacol or (f) 4-methylphenol. Positive values indicate preference for food supplemented with odor. $N=12$. Data shown are means $\pm \mathrm{SE}$ for females (left) and males (right). Letters indicate $P<0.05$ using Tukey's post hoc test. (PDF $104 \mathrm{~kb}$ )

Additional file 6: Figure S5. Dry mass and measurements of metabolism. (a, b) Dry mass $(N=10)$, (c, $\mathbf{d})$ adjusted triglyceride levels $(N=3),(\mathbf{e}, \mathbf{f})$ adjusted glucose $(N=3)$, and $(\mathbf{g}, \mathbf{h})$ adjusted glycogen measurements $(\mathrm{N}=3)$ for lines selected for increased and decreased behavioral responses to 4-ethylguaiacol and 4-methylphenol. Data shown are means \pm SE for females and males (left and right columns, respectively). Letters indicate $P<0.05$ using Tukey's post hoc test. (PDF 207 kb)

Additional file 7: Figure S6. Categorization of differentially expressed genes among lines selected for differences in behavioral responses to 4-ethylguaiacol into (a) biological process, (b) molecular function, and (c) cellular component gene ontology terms. (PDF 18 kb)

\section{Abbreviations}

$\mathrm{X}^{2}$ : Chi-square value; 4EG: 4-ethylguaiacol; 4MP : 4-methylphenol; CPM: Counts per million; Df: Degrees of freedom; EA: Ethyl acetate; F: F ratio; FC : Fold count; FDR: False discovery rate; GO: Gene ontology; GWA: Genome-wide association; LR: Likelihood ratio; MH: Methyl hexanoate; OSN: Olfactory sensory neuron; P: P-value; S.S.: Sum of squares; TAG: Triglyceride

\section{Acknowledgements}

We would like to thank Peter Andolfatto, John Layne, and Lu Yang for help with RNA-seq analyses and/or helpful discussions. We also thank Allie Elchert, Zachary Moore, Mary Shaw, and members of the Rollmann and Andolfatto labs for technical assistance. We thank TRiP at Harvard Medical School (NIH/ NIGMS R01-GM084947) for transgenic RNAi stocks.

\section{Funding}

This work was supported by the National Institutes of Health (GM080592 to SMR). EB was supported by the University of Cincinnati Graduate School Dean's Fellowship, while the National Science Foundation REU (DBI-1262863) supported RP.

\section{Availability of data and materials}

The data sets supporting the results of this article are included within the article and its additional files.

\section{Authors' contributions}

$E B$ and SMR designed the study and wrote the manuscript. EB, RP, and CP conducted the experiments. EB analyzed the data. All authors read and approved of the manuscript.

\section{Ethics approval and consent to participate}

Not applicable.

\section{Consent for publication}

Not applicable.

\section{Competing interests}

The authors declare that they have no competing interests.

\section{Publisher's Note}

Springer Nature remains neutral with regard to jurisdictional claims in published maps and institutional affiliations.

\section{Author details}

'Department of Biological Sciences, University of Cincinnati, Cincinnati, $\mathrm{OH}$ 45221-0006, USA. ${ }^{2}$ Department of Biology, Xavier University, Cincinnati, OH 45207, USA.
Received: 6 April 2017 Accepted: 23 October 2017

Published online: 13 November 2017

\section{References}

1. Apfeld J, Kenyon C. Regulation of lifespan by sensory perception in Caenorhabditis elegans. Nature. 1999:402:804-9.

2. Alcedo J, Kenyon C. Regulation of C. elegans longevity by specific gustatory and olfactory neurons. Neuron. 2004;41:45-55.

3. Libert S, Zwiener J, Chu X, Vanvoorhies W, Roman G, Pletcher S. Regulation of Drosophila life span by olfaction and food-derived odors. Science. 2007; 315:1133-7.

4. Poon P, Kuo TH, Linford N, Roman G, Pletcher S. Carbon dioxide sensing modulates lifespan and physiology in Drosophila. PLoS Biol. 2010;8: e1000356.

5. Gendron CM, Kuo TH, Harvanek ZM, Chung BY, Yew JY, Dierick HA, Pletcher SD. Drosophila life span and physiology are modulated by sexual perception and reward. Science. 2014;343:544-8.

6. Vosshall LB, Stocker RF. Molecular architecture of smell and taste in Drosophila. Annu Rev Neurosci. 2007;30:505-33.

7. CY S, Menuz K, Calrson JR. Olfactory perception: receptors, cells, and circuits. Cell. 2009;139:45-59

8. Wilson Rl. Early olfactory processing in Drosophila: mechanisms and principles. Annu Rev Neurosci. 2013;36:217-41

9. Laissue P, Reiter C, Hiesinger P, Halter S, Fischbach K, Stocker R. Threedimensional reconstruction of the antennal lobe in Drosophila melanogaster J Comp Neurol. 1999:405:543-52.

10. Vosshall L, Wong A, Axel R. An olfactory sensory map in the fly brain. Cell. 2000:102:147-59.

11. Dobritsa A, Naters W, Warr C, Steinbrecht R, Carlson J. Integrating the molecular and cellular basis of odor coding in the Drosophila antenna. Neuron. 2003:37:827-41.

12. Hallem E, Ho MG, Carlson JR. The molecular basis of odor coding in the Drosophila antenna. Cell. 2004;117:965-79.

13. Couto A, Alenius M, Dickson B. Molecular, anatomical, and functional organization of the Drosophila olfactory system. Curr Biol. 2005;15:1535-47.

14. Clyne P, Warr C, Freeman M, Lessing D, Kim J, Carlson JA. Novel family of divergent seven-transmembrane proteins candidate odorant receptors in Drosophila. Neuron. 1999;22:327-38.

15. Robertson H, Warr C, Carlson J. Molecular evolution of the insect chemoreceptor gene superfamily in Drosophila melanogaster. Proc Natl Acad Sci U S A. 2003;100(Suppl2):14537-42.

16. Larsson M, Domingos A, Jones W, Chiappe M, Amrein H, Vosshall L. Or83b encodes a broadly expressed odorant receptor essential for Drosophila olfaction. Neuron. 2004:43:703-14.

17. Sato K, Pellegrino M, Nakagawa T, Nakagawa T, Vosshall L, Touhara K. Insect olfactory receptors are heteromeric ligand-gated ion channels. Nature. 2008; 452:1002-6

18. Wicher D, Schäfer R, Bauernfeind R, Stensmyr MC, Heller R, Heinemann SH, Hansson BS. Drosophila odorant receptors are both ligand-gated and cyclicnucleotide-activated cation channels. Nature. 2008:452:1007-11.

19. Marin E, Jefferis G, Komiyama T, Zhu H, Luo L. Representation of the glomerular olfactory map in the Drosophila brain. Cell. 2001;109:243-55.

20. Wong A, Wang J, Axel R. Spatial representation of the glomerular map in the Drosophila protocerebrum. Cell. 2002;109:229-41.

21. Tanaka N, Awasaki T, Shimada T, Ito K. Integration of chemosensory pathways in the Drosophila second-order olfactory centers. Curr Biol. 2004;14:449-57.

22. Jefferis GS, Potter CJ, Chan AM, Marin EC, Rohlfing T, Maurer CR, Luo L. Comprehensive maps of Drosophila higher olfactory centers: spatially segregated fruit and pheromone representation. Cell. 2007:128:1187-203.

23. Gao Q, Yuan B, Chess A. Convergent projections of Drosophila olfactory neurons to specific glomeruli in the antennal lobe. Nat Neurosci. 2000; 3:780-5.

24. Wang J, Wong A, Flores J, Vosshall L, Axel R. Two-photon calcium imaging reveals an odor-evoked map of activity in the fly brain. Cell. 2003;112:271-82.

25. Wang P, Lyman R, Shabalina S, Mackay TF, Anholt RR. Association of polymorphisms in odorant-binding protein genes with variation in olfactory response to benzaldehyde in Drosophila. Genetics. 2007:177:1655-65.

26. Wang P, Lyman R, Mackay TF, Anholt RR. Natural variation in odorant recognition among odorant-binding proteins in Drosophila melanogaster. Genetics. 2010;184:759-67. 
27. Arya G, Weber A, Wang P, Magwire M, Negron Y, Mackay TF, Anholt RR. Natural variation, functional pleiotropy and transcriptional contexts of odorant binding protein genes in Drosophila melanogaster. Genetics. 2010 186:1475-85.

28. Rollmann SM, Wang P, Date P, West S, Mackay TF, Anholt RR. Odorant receptor polymorphisms and natural variation in olfactory behavior in Drosophila melanogaster. Genetics. 2010;186:687-97.

29. Richgels P, Rollmann S. Genetic variation in odorant receptors contributes to variation in olfactory behavior in a natural population of Drosophila melanogaster. Chem Senses. 2012;37:229-40.

30. Brown E, Layne J, Zhu C, Jegga A, Rollmann S. Genome-wide association mapping of natural variation in odour-guided behaviour in Drosophila. Genes Brain Behav. 2013;12:503-15.

31. Swarup S, Huang W, Mackay TF, Anholt RR. Analysis of natural variation reveals neurogenetic networks for Drosophila olfactory behavior. Proc Natl Acad Sci U S A. 2013;110:1017-22.

32. Arya G, Magwire M, Huang W, Serrano-Negron Y, Mackay TF, Anholt RR. The genetic basis for variation in olfactory behavior in Drosophila melanogaster. Chem Senses. 2015;40:233-43.

33. Rollmann SM, Magwire MM, Morgan TJ, Ozsoy ED, Yamamoto A, Mackay TF, Anholt RR. Pleiotropic fitness effects of the Tre1-Gr5a region in Drosophila melanogaster. Nature Genet. 2006;38:824-9.

34. Ostojic I, Boll W, Waterson MJ, Chan T, Chandra R, Pletcher SD, Alcedo J. Positive and negative gustatory inputs affect Drosophila lifespan partly in parallel to dFOXO signaling. Proc Natl Acad Sci U S A. 2014; 111(22):8143-8.

35. Pool AH, Scott K. Feeding regulation in Drosophila. Curr Opin Neurobiol. 2014;29:57-63.

36. Wright $\mathrm{G}$. To feed or not to feed: circuits involved in the control of feeding in insects. Curr Opin Neurobiol. 2016:41:87-91.

37. Sachse S, Beshel J. The good, the bad, and the hungry: how the central brain codes odor valence to facilitate food approach in Drosophila. Curr Opin Neurobiol. 2016:40:53-8.

38. Kim SM, CY S, Wang JW. Neuromodulation of innate behaviors in Drosophila. Annu Rev Neurosci. 2017;40:327-48.

39. Brown MR, Crim JW, Arata RC, Cai HN, Chun C, Shen P. Identification of a Drosophila brain-gut peptide related to the neuropeptide $Y$ family. Peptides. 1999;20:1035-42.

40. Root CM, Ko Kl, Jafari A, Wang JW. Presynaptic facilitation by neuropeptide signaling mediates odor-driven food search. Cell. 2011;145:133-44.

41. Beshel J, Zhong Y. Graded encoding of food odor value in the Drosophila brain. J Neurosci. 2013;33:15693-704.

42. Nordström K. Formation of ethyl acetate in fermentation with brewer's yeast. J Inst Brew. 1960;67:173-81.

43. Tressel R, Drawert F. Biogenesis of banana volatiles. J Agr Food Chem. 1973; 21:560-5.

44. Comuzzo P, Tat L, Tonizzo A, Battistutta F. Yeast derivatives (extracts and autolysates) in winemaking: release of volatile compounds and effects on wine aroma volatility. Food Chem. 2006;99:217-30.

45. Dweck H, Ebrahim S, Farhan A, Hansson B, Stensmyr M. Olfactory proxy detection of dietary antioxidants in Drosophila. Curr Biol. 2015;25:455-66.

46. Huang W, Richards S, Carbone MA, Zhu D, Anholt RR, Ayroles JF, Duncan L, Jordan KW, Lawrence F, Magwire MM, Warner CB, Blankenburg K, Han Y, Javaid M, Jayaseelan J, Jhangiani SN, Muzny D, Ongeri F, Perales L, Wu YQ, Zhang Y, Zou X, Stone EA, Gibbs RA, Mackay TF. Epistasis dominates the genetic architecture of Drosophila quantitative traits. Proc Natl Acad Sci U S A. 2012;109:15553-9.

47. Schwasinger-Schmidt T, Kachman S, Harshman L. Evolution of starvation resistance in Drosophila melanogaster: measurement of direct and correlated responses to artificial selection. J Evol Biol. 2012;25:378-87.

48. Ja WW, Carvalho G, Mak EM, de las Rosa NN, Fang AY, Liong JC, Brummel T, Benzer S. Prandiology of Drosophila and the CAFE assay. Proc Natl Acad Sci U S A 2007;104:8253-8256.

49. Edgar B. How flies get their size: genetics meets physiology. Nature Rev Genet. 2006;7:907-16.

50. Attrill H, Falls K, Goodman JL, Millburn GH, Antonazzo G, Rey AJ, Marygold SJ. FlyBase: establishing a gene group resource for Drosophila melanogaster. Nucleic Acids Res. 2016:44:D786-92.

51. Ni JQ, Markstein M, Binari R, Pfeiffer BD, Liu LP, Villalta C, Booker M, Perkins $L A$, Perrimon N. Vector and parameters for targeted transgenic RNA interference in Drosophila melanogaster. Nat Methods. 2007;5:49-51.
52. Ni JQ, Liu LP, Binari R, Hardy R, Shim HS, Cavallaro A, Booker M, Pfeiffer BD, Markstein M, Wang H, Villalta C, Laverty TR, Perkins LA, Perrimon NA. Drosophila resource of transgenic RNAi lines for neurogenetics. Genetics. 2009:182:1089-100.

53. Brand A, Perrimon N. Targeted gene expression as a means of altering cell fates and generating dominant phenotypes. Dev Camb Engl. 1993; 118:401-15.

54. Jefferis GS, Marin EC, Stocker RF, Luo L. Target neuron prespecification in the olfactory map of Drosophila. Nature. 2001;414:204-8.

55. Shiraiwa T. Multimodal chemosensory integration through the maxillary palp in Drosophila. PLoS One. 2008;3(5):e2191.

56. Singh $\mathrm{R}$, Nayak $\mathrm{S}$. Fine structure and primary sensory projections of sensilla on the maxillary palp of Drosophila melanogaster Meigen (Diptera : Drosophilidae). Int J Insect Morphol Embryol. 1985;14:291-306.

57. de Bruyne M, Clyne PJ, Carlson JR. Odor coding in a model olfactory organ: the Drosophila maxillary palp. J Neurosci. 1999;19(1):4520-32.

58. Nowotny T, de Bruyne M, Berna AZ, Warr CG, Trowell SC. Drosophila olfactory receptors as classifiers for volatiles from disparate real world applications. Bioinspir Biomim. 2014;9:1-13.

59. CY S, Wang JW. Modulation of neural circuits: how stimulus context shapes innate behavior in Drosophila. Curr Opin Neurobiol. 2014;29:9-16.

60. Suh GS, Wong AM, Hergarden AC, Wang JW, Simon AF, Benzer S, Axel R, Anderson DJA. Single population of olfactory sensory neurons mediates an innate avoidance behavior in Drosophila. Nature. 2004;431:854-9.

61. Turner SL, Ray A. Modification of $\mathrm{CO} 2$ avoidance behavior in Drosophila by inhibitory odorants. Nature. 2009;461:277-82.

62. CY S, Menuz K, Reisert J, Carlson JR. Non-synaptic inhibition between grouped neurons in an olfactory circuit. Nature. 2012;492:66-72.

63. Clark RM, Zera AJ, Behmer ST. Metabolic rate is canalized in the face of variable life history and nutritional environment. Funct Ecol. 2016;30:922-31.

64. Swarup S, Williams T, Anholt RR. Functional dissection of odorant binding protein genes in Drosophila melanogaster. Genes Brain Behav. 2011;10:648-57

65. Vogt RG. Molecular basis of pheromone detection in insects. In: Gilbert LI, latro K, Gill S, editors. Comprehensive insect physiology biochemistry, pharmacology and molecular biology. London: Elsevier; 2005. p. 753-804.

66. Shen P, Cai HN. Drosophila neuropeptide F mediates integration of chemosensory stimulation and conditioning of the nervous system by food. J Neurobiol. 2001;47(1):16-25.

67. Wu Q, Wen T, Lee G, Park JH, Cai HN, Shen P. Developmental control of foraging and social behavior by the Drosophila neuropeptide Y-like system. Neuron. 2003;39:147-61.

68. Erion R, Sehgal A. Regulation of insect behavior via the insulin-signaling pathway. Front Physiol. 2013:4:353.

69. Nassel DR, Liu Y, Luo J. Insulin/IGF signaling and its regulation in Drosophila. Gen Comp Endocrinol. 2015;221:255-66.

70. Porte D Jr, Baskin DG, Schwartz MW. Insulin signaling in the central nervous system: a critical role in metabolic homeostasis and disease from C. elegans to humans. Diabetes 2005;54(5):1264-1276.

71. Alvarez-Ponce D, Aguadé M, Rozas J. Network-level molecular evolutionary analysis of the insulin/TOR signal transduction pathway across 12 Drosophila genomes. Genome Res. 2009;19(2):234-42.

72. Wang $M$, Wang $Q$, Wang Z, Wang $Q$, Zhang $X$, Pan $Y$. The molecular evolutionary patterns of the insulin/FOXO signaling pathway. Evol Bioinformatics Online. 2013;9:1-16.

73. Garlapow ME, Huang W, Yarboro MT, Peterson KR. Quantitative genetics of food intake in Drosophila melanogaster. PLoS One. 2015;10(9):e0138129.

74. Garlapow ME, Everett LJ, Zhou S, Gearhart AW, Fay KA, Huang W, Morozoba TV, Arya GH, Turlapati L, St. Armour G, Hussain YN, McAdams SE, Fochler S, Mackay TF. Genetic and genomic response to selection for food consumption in Drosophila melanogaster. Behav Genet 2017;47(2):227-243.

75. Jhaveri $D$, Sen A, Reddy $V$, Rodrigues $V$. Sense organ identity in the Drosophila antenna is specified by the expression of the proneural gene atonal. Mech Dev. 2000;99:101-11.

76. Kumar JP, Moses KEGF. Receptor and notch signaling act upstream of eyeless/Pax6 to control eye specification. Cell. 2001;104:687-97.

77. Shilo B. Signaling by the Drosophila epidermal growth factor receptor pathway during development. Exp Cell Res. 2003;284:140-9.

78. Sen A, Kuruvilla D, Pinto L, Sarin A, Rodrigues V. Programmed cell death and context dependent activation of the EGF pathway regulate gliogenesis in the Drosophila olfactory system. Mech Dev. 2004;121:65-78. 
79. Kurachi H, Adachi H, Ohtsuka S, Morishige K, Amemiya K, Keno Y, Shimomura I, Tokunaga K, Miyake A, Matsuzawa Y, Tanizawa O. Involvement of epidermal growth factor in inducing obesity in ovariectomized mice. Am J Phys. 1993;265:E323-31.

80. Adachi H, Kurachi H, Homma H, Adachi K, Imai T, Morishige K, Matsuzawa Y, Miyake A. Epidermal growth factor promotes adipogenesis of 3T3-L1 cell in vitro. Endocrinology. 1994;135(5):1824-30.

81. Kanamori Y, Saito A, Hagiwara-Komoda Y, Mitsumasu K, Kikuta S, Watanabe M, Cornette R, Kikawada T, Okuda T. The trehalose transporter 1 gene sequence is conserved in insects and encodes proteins with different kinetic properties involved in trehalose import into peripheral tissues. Inest Biochem Mol Biol. 2010;40:30-7.

82. Menuz K, Larter NK, Park J, Carlson JR. An RNA-seg screen of the Drosophila antenna identifies a transporter necessary for ammonia detection. PLoS Genet. 2014;10:e1004810.

83. Abdelilah-Seyfried S, Chan YM, Zeng C, Justice NJ, Younger-Shepherd S, Sharp LE, Barbel S, Meadows SA, Jan LY, Jan YNA. Gain-of-function screen for genes that affect the development of the Drosophila adult external sensory organ. Genetics. 2000;155:733-52.

84. Morrison DK, Murakami MS, Cleghon V. Protein kinases and phosphatases in the Drosophila genome. J Cell Biol. 2000;150(2):F57-62.

85. Manning G, Plowman GD, Hunter T, Sudarsanam S. Evolution of protein kinase signaling from yeast to man. Trends Biochem Sci. 2002;27(10):514-20.

86. Sopko R, Foos M, Vinayagam A, Zhai B, Binari R, Hu Y, Randklev S, Perkins LA, Gygi SP, Perrimon N. Combining genetic perturbations and proteomic to examine kinase-phosphatase networks in Drosophila embryos. Dev Cell. 2014;31:114-27.

87. Wei J, Zhao AZ, Chan GCK, Baker LP, Impey S, Beavo JA, Storm DR. Phosphorylation and inhibition of olfactory adenylyl cyclase by CaM kinase II neurons: a mechanism for attenuation of olfactory signals. Neuron. 1998;21:495-504.

88. Guven-Ozkan T, Davis R. Functional neuroanatomy of Drosophila olfactory memory formation. Learn Mem. 2014;21:519-26.

89. Berthoud HR. Metabolic and hedonic drives in the neural control of appetite: who is the boss? Curr Opin Neurobiol. 2011;21:888-96.

90. Sheriff S, Chance WT, Fischer JE, Balasubramaniam A, Neuropeptide Y. Treatment and food deprivation increase cyclic AMP response elementbinding in rat hypothalamus. Mol Pharmacol. 1997;51:597-604.

91. Yu X, Murao K, Sayo Y, Imachi H, Cao WM, Ohtsuka S, Niimi M, Tokumitsu H, Inuzuka $H$, Wong NCW, Kobayashi R, Ishida T. The role of calcium/ calmodulin-dependent protein kinase cascade in glucose upregulation of insulin gene expression. Diabetes. 2004;53:1475-81.

92. Dietzl G, Chen D, Schnorrer F, KC S, Barinova Y, Fellner M, Gasser B, Kinsey K, Oppel S, Scheiblauer S, Couto A, Marra V, Keleman K, Dickson BJA. Genomewide transgenic RNAi library for conditional gene inactivation in Drosophila. Nature. 2007:448:151-6.

93. Helfand S, Carlson J. Isolation and characterization of an olfactory mutant in Drosophila with a chemically specific defect. Proc Natl Acad Sci. 1989;86: 2908-12.

94. Jordan K, Morgan T, Mackay TF. Quantitative trait loci for locomotor behavior in Drosophila melanogaster. Genetics. 2006;174:271-84.

95. Deshpande SA, Carvalho GB, Amador A, Phillips AM, Hoxha S, Lizotte KJ, Ja WW. Quantifying Drosophila food intake: comparative analysis of current methodology. Nat Methods. 2014;11:535-40.

96. Linford N, Bilgir C, Ro J, Pletcher S. Measurement of lifespan in Drosophila melanogaster. J Vis Exp. 2013;71:e50068.

97. Tennessen J, Barry W, Cox J, Thummel C. Methods for studying metabolism in Drosophila. Methods. 2014;68:105-15.

98. Martin M. Cutadapt removes adapter sequences from high-throughput sequencing reads. EMBnet. Journal. 2011;17:10-2.

99. Dobin A, Davis CA, Schlesinger F, Drenkow J, Zaleski C, Jha S, Batut P Chaisson M, Gingeras TR. STAR: ultrafast universal RNA-seq aligner. Bioinformatics. 2013;29(1):15-21.

100. Robinson MD, McCarthy DJ, Smyth GK. EdgeR: a Bioconductor package for differential expression analysis of digital gene expression data. Bioinformatics. 2010;26(1):139-40.

101. Mi H, Muruganujan A, Casagrande JT, Thomas PD. Large-scale gene function analysis with the PANTHER classification system. Nat Protoc. 2013;8:1551-66.

102. Mi H, Sagar P, Muruganujan A, Casagrande JT, Thomas PDPANTHER. Version 10: expanded protein families and functions, and analysis tools. Nucleic Acids Res. 2016:44:D336-42.

\section{Submit your next manuscript to BioMed Central and we will help you at every step:}

- We accept pre-submission inquiries

- Our selector tool helps you to find the most relevant journal

- We provide round the clock customer support

- Convenient online submission

- Thorough peer review

- Inclusion in PubMed and all major indexing services

- Maximum visibility for your research

Submit your manuscript at www.biomedcentral.com/submit
) Biomed Central 